\title{
Imaging features, clinicopathological analysis and diagnostic strategy of IgG4-related hypertrophic pachymeningitis
}

\author{
Yilei Zhao, Jingfeng Xu \\ Department of Radiology, the First Affiliated Hospital, School of Medicine, Zhejiang University, Hangzhou, China \\ Contributions: (I) Conception and design: Y Zhao; (II) Administrative support: All authors; (III) Provision of study materials or patients: Y Zhao; \\ (IV) Collection and assembly of data: All authors; (V) Data analysis and interpretation: All authors; (VI) Manuscript writing: All authors; (VII) Final \\ approval of manuscript: All authors. \\ Correspondence to: Yilei Zhao. Department of Radiology, the First Affiliated Hospital, School of Medicine, Zhejiang University, No.79, Qingchun \\ Road, Hangzhou 310003, China. Email: 1309035@zju.edu.cn.
}

Background: This study was conducted to summarize the clinical, magnetic resonance imaging (MRI) and pathological features of IgG4-realated hypertrophic pachymeningitis (IgG4-RHP) and its differential diagnosis from similar diseases.

Methods: Data of IgG4-RHP patients admitted to Department of Neurology, Neurosurgery and Infection, the First Affiliated Hospital of Medical School of Zhejiang University from January 1, 2015 to July 31, 2019 were collected and their clinical symptoms, laboratory examinations, imaging and pathological features were investigated. At the same time, the clinicopathological and imaging findings of other dura thickening diseases diagnosed in our hospital were compared and analyzed.

Results: The clinical symptoms of 4 IgG4-RHP patients include chronic headache and cranial nerves injury, etc. Levels of serum IgG4 and cerebrospinal fluid (CSF) IgG4 increased in all patients. Focal enhancement of dura mater could be seen on plain and enhanced cranial MRI. Pathological results were consistent with IgG4-RHP symptoms. Among other diseases that cause dural thickening, the content of serum C-reactive protein in patients with Rosai-Dorfman disease declined. Patients with intracranial hypotension syndrome often have postural headache. Patients with tuberculous meningitis can have previous pulmonary tuberculosis. The diagnosis of patients with atypical meningioma depends on the results of operation and pathology. Patients with central nervous system leukemia can be diagnosed with reference to the results of laboratory results.

Conclusions: The clinicopathological and imaging manifestations of IgG4-RHP are summarized in this study. Meanwhile, the clinical data of several other diseases with similar imaging characteristics are analyzed in order to clarify the diagnostic strategy of IgG4-RHP and provide help for the next treatment.

Keywords: Meningitis; IgG4-related hypertrophic pachymeningitis (IgG4-RHP); magnetic resonance imaging (MRI); pathology

Submitted Nov 05, 2019. Accepted for publication Jun 28, 2020.

doi: 10.21037/apm-19-452

View this article at: http://dx.doi.org/10.21037/apm-19-452

\section{Introduction}

Immunoglobulin G4-related disease (IgG4-RD) is defined as a fibroblastic inflammatory immune disease that multiple organs are involved. As a systemic disease, it is gradually recognized and accepted, linking much individual organ damage together, which was considered irrelevant in the past (1). IgG4-RD damage can be found in the lung, mediastinum, liver, and pancreas. So far many diseases including acute intermittent porphyria (AIP), Riedel thyroiditis, tubulointerstitial nephritis (TIN), inflammatory pseudotumor, and retroperitoneal fibrosis have been categorized as IgG4-RD. Dura mater that IgG4- 
$\mathrm{RD}$ is involved in will cause IgG4-related hypertrophic pachymeningitis (IgG4-RHP) $(2,3)$. Many of patients with specific hypertrophic cranial pachymeningitis (HCP) by staining IgG and IgG4 histological specimens, so those patients were diagnosed as IgG4-RHP. Therefore, some scholars believed that IgG4-RHP may be the most common cause of idiopathic HCP. Based on the cases confirmed by pathology, this study discussed the clinical features and diagnostic strategy of IgG4-RHP in order to provide help for clinicians (3). HCP is a rare inflammatory proliferative disease characterized by local or diffuse thickening and fibrosis of dura mater. Its onset is latent and the pathogeny is complex. The clinical symptoms are chronic headache, epilepsy, psychosis, etc. HCP is involved in multiple sets of cranial nerves, manifesting as corresponding cranial nerves damage, and the most common damaged cranial nerves are VIII, VI, IX cranial nerves. Some RHP associated with hypertrophic spinal pachymeningitis (HSP) is called hypertrophic pachymeningitis $(4,5)$. However, it is easy to be misdiagnosed as meningioma, lymphoma, metastasis and other intracranial space occupying lesions if only according to the imaging findings. Some patients with IgG4 related diseases but without clinical symptoms of nervous system were examined with MRI.

Owing to the presence of dura meningitis, MRI should be performed in patients with IgG4 related diseases to determine whether there is dura involvement. IgG4RHP is a rare autoimmune disease. IgG4-RHP is hard to be diagnosed and identified on account of its latent onset, which makes clinical and imaging diagnosis difficult. Clinical symptoms, imaging and pathological characteristics, laboratory results in 4 cases were analyzed retrospectively to assess the imaging features and pathological characteristics and improve the understanding of IgG4-RHP. In addition, several diseases similar to IgG4-RHP were summarized.

We present the following article in accordance with the STROBE Reporting Checklist (available at http://dx.doi. org/10.21037/apm-19-452).

\section{Methods}

\section{Research objects}

Objects data of 4 IgG4-RHP patients admitted to Department of Neurology, Neurosurgery and Infection, the First Affiliated Hospital of Medical School of Zhejiang University from January 1, 2015 to July 31, 2019 were collected and their clinical symptoms, laboratory examinations, imaging and pathological features before and after treatment were analyzed. All 4 cases were male, average $(39.1 \pm 11.6)$ years old. All patients were diagnosed on the basis of clinical symptoms, signs and accessory examination results and met the diagnostic criteria proposed by Deshpande in 2012 (6). Furthermore, RosaiDorfman disease, intracranial hypotension syndrome, tuberculous meningitis, atypical meningiomas and central nervous system leukemia were collected in one case each to explore their clinical symptoms, laboratory examination and imaging and pathological features before and after treatment. The study was approved by the First Affiliated Hospital, School of Medicine, Zhejiang University ethics committee (No. 2019-1376) and conducted in accordance with the Declaration of Helsinki (as revised in 2013). Because of the retrospective nature of the research, the requirement for informed consent was waived.

\section{Laboratory examination}

The blood routine, blood biochemistry, C-reactive protein (CRP), D-Dimer, autoimmune antibodies and parallel examined cerebrospinal fluid (CSF) routine and biochemical detection of all patients were examined.

\section{Imaging examination}

Patients were maintained at supine position to take T1WI (T1-weighted imaging) and T2WI (T2-weighted imaging) axial scanning by 3.0 T magnetic resonance scanner produced by GE Discovery MR 750W 3.0T. Diffusion weighted imaging used ECG-gating, free breathing or non-breathhold spin echo planar imaging, which aimed to denoise.

\section{Neuropathology examination}

Four patients were tested by the 3D directional minimal invasive brain biopsy. Pathological specimens were stained with $\mathrm{HE}$ and immunohistochemistry, including CD3, CD20, GFAP, Vimentin, Epithelial membrane antigen (EMA), IgG, IgG4, etc.

\section{Results}

\section{Clinical features}

All the 4 patients had headache as the initial symptom, and 2 of them had cranial nerves injury, including acoustic nerve, optic nerve and trigeminal nerve. Specific clinical 
Table 1 Clinical features in IgG4-RHP patients and laboratory results

\begin{tabular}{|c|c|c|c|c|c|c|c|}
\hline $\begin{array}{l}\text { Case } \\
\text { Number }\end{array}$ & Gender & Age (year) & Main clinical manifestation & $\begin{array}{l}\text { CSF IgG } \\
(\mathrm{mg} / \mathrm{L})\end{array}$ & $\begin{array}{l}\text { CSF oligoclonal } \\
\text { band }\end{array}$ & $\begin{array}{l}\text { Serum IgG4 } \\
(\mathrm{mg} / \mathrm{dL})\end{array}$ & Imaging manifestation \\
\hline 1 & Male & 38 & $\begin{array}{l}\text { Intermittent right temporal } \\
\text { headache for } 5 \text { years, right } \\
\text { ear hearing loss for } 1 \text { year }\end{array}$ & 590 & Negative & 165 & $\begin{array}{l}\text { Meningeal thickening of middle } \\
\text { cranial fossa }\end{array}$ \\
\hline 2 & Male & 46 & $\begin{array}{l}\text { Intermittent temporal } \\
\text { headache for } 2 \text { years, right } \\
\text { eye vision declined for } \\
2 \text { weeks }\end{array}$ & 610 & Negative & 143 & $\begin{array}{l}\text { Meningeal thickening of } \\
\text { cerebellum }\end{array}$ \\
\hline 3 & Male & 51 & $\begin{array}{l}\text { Parietal headache for } \\
3 \text { months, right side } \\
\text { numbness for } 2 \text { weeks }\end{array}$ & 543 & Positive & 152 & $\begin{array}{l}\text { Right temporal-parietal dura } \\
\text { enhancement }\end{array}$ \\
\hline 4 & Male & 41 & $\begin{array}{l}\text { Intermittent total headache } \\
\text { for } 3 \text { years }\end{array}$ & 530 & Positive & 140 & $\begin{array}{l}\text { Bilateral parietal dura } \\
\text { enhancement }\end{array}$ \\
\hline
\end{tabular}

IgG4-RHP, IgG4-related hypertrophic pachymeningitis, Figures 1,2 the same; normal range of lgG in CSF: 10-40 mg/L, normal range of IgG4 in serum: $<135 \mathrm{mg} / \mathrm{dL}$.

manifestations were presented in Table 1.

\section{Laboratory examination}

The detection of serum IgG and IgG4 was lack of specificity and sensitivity for the diagnosis of the disease. The blood routine, blood biochemistry, CRP, D-Dimer, autoimmune antibodies and the parallel examination of $\mathrm{CSF}$ and biochemical detection showed negative results. When the IgG index in CSF increases and the igg4loc value exceeds 0.47 , it is necessary to identify other factors. The IgG synthesis rate in CSF rose in all the 4 patients; the oligoclonal bands were positive in 2 patients; IgG4 level in serum was elevated in all the 4 patients (Table 1).

\section{Imaging features}

MRI scan results of all 4 patients showed dura enhancement, 1 case involved temporal lobe, 1 case involved middle cranial fossa, 1 case involved cerebellum, 1 case involved parietal lobe and no extensive dura involvement (Figure 1A,B, Figure 2A,B,C).

\section{Neuropatbology features}

The results of dural biopsies in 4 patients showed that there was hyperplasia of fibrous tissue, local mat like arrangement, occlusive phlebitis, with a large number of plasma cells, lymphocytes and scattered eosinophils infiltration. Immunohistochemistry showed that the number of IgG and IgG4 positive plasma cells increased. The number of IgG4 positive plasma cells in each high-power field was more than 10 , IgG4/IgG was more than $40 \%$ (Figure 3).

\section{Relevant differential diagnosis}

The clinical data of Rosai-Dorfman disease, intracranial hypotension syndrome, tuberculous meningitis, atypical meningiomas and central nervous system leukemia were analyzed retrospectively. Cranial MRI is an important examination for finding lesions, which are located in tentorium cerebelli, brain Lian, lobar surface, near the superior sagittal sinus, etc. The imaging results of the above diseases were similar to IgG4-RHP. Some of these diseases were differentiated by laboratory examination or surgical operation. A case of Rosai Dorfman disease was confirmed by pathology (Figure 4). See Table 2 for specific case information.

\section{Discussion}

IgG4-RD can affect multiple organs and cause corresponding functional damage. HCP is a rare disease characterized by hypertrophic intracranial dura mater and fibrosis inflammatory lesion. The causes of HCP are not yet clear, which is mainly of two kinds, secondary and idiopathic $(7,8)$. Secondary causes of HCP include 

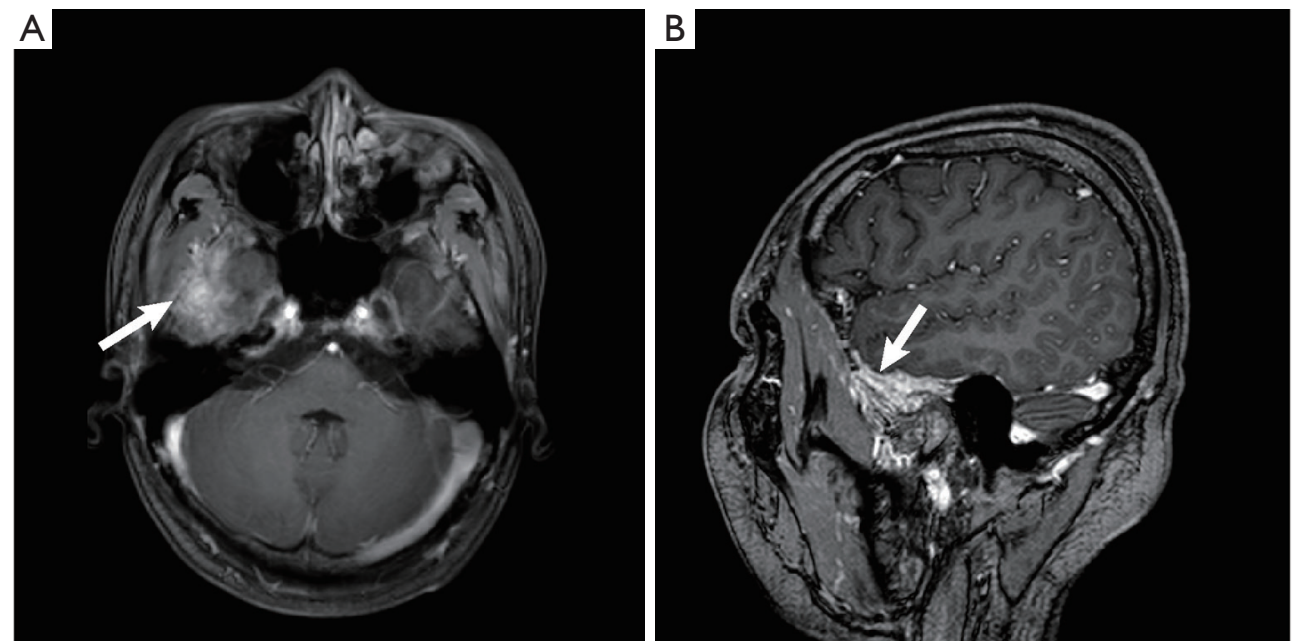

Figure 1 Brain MRI image of patient 1. (A) Cross-sectional MRI showed thickening of meninges in the middle cranial fossa; (B) sagittal MRI showed thickening of meninges in middle cranial fossa. The arrow points to the thickened dura.
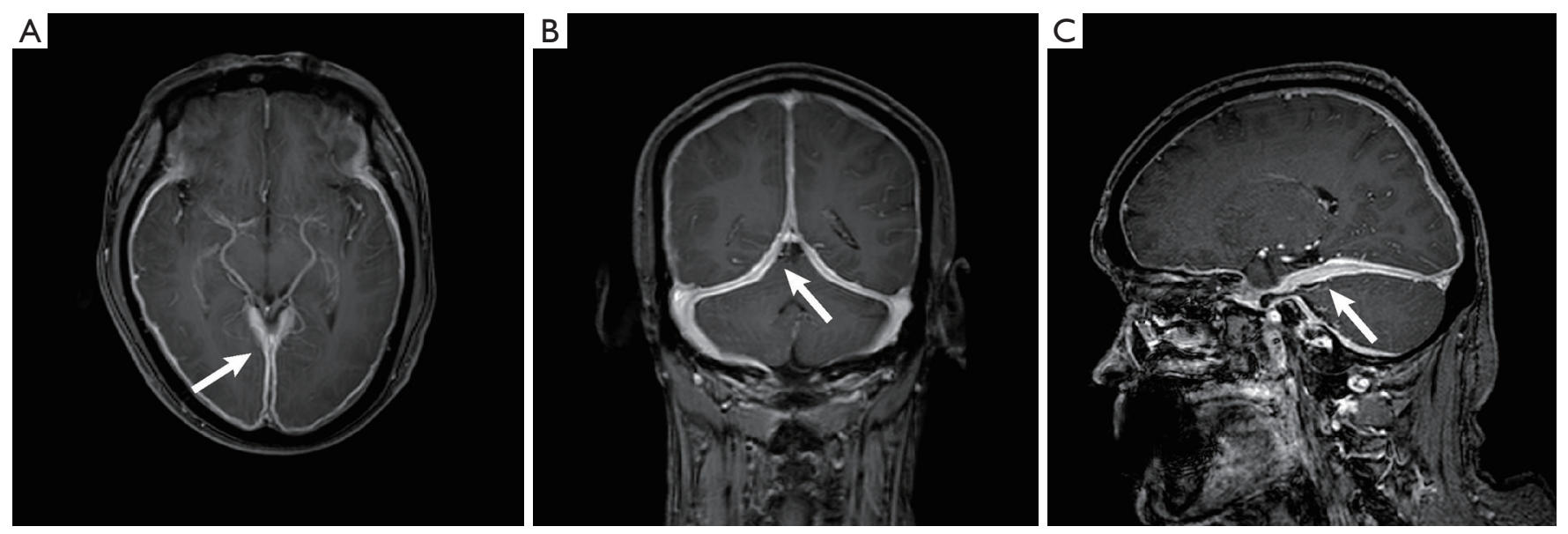

Figure 2 Brain MRI image of patient 2. (A) T2WI cross section shows dural thickening; (B) T2WI coronal position shows dural thickening; (C) T2WI sagittal position shows dural thickening. The arrow points to the thickened dura.

infection, autoimmune disease, tumor, etc. Most of HCP are of unknown causes, which is called idiopathic HCP (IHCP), and most scholars believe that IHCP is related to autoimmunity. Many IHCP are related to IgG4, which called IgG4-realated HCP (IgG4-RHCP). In the dura mater inflammation, IgG4 positive plasma cells are infiltrated, and stained IgG4 can be seen in pathological section. HCP is more frequently seen on old people, among which male are more than female (9-12). Its main symptoms are chronic headache, cranial nerve palsy, cerebellar ataxia while epileptic attack and papilledema are rare. The degree of headache usually increased gradually (incidence is about $90 \%$ ), usually with distending pain of total or postural headache. Headache is likely to be caused by a combination of dura inflammatory stimulation and increased intracranial pressure caused by thickening dura mater $(2,13)$. In this study, the onset of disease is that patients suffer from bilateral frontal pain. The involvement of cranial nerves is mainly induced by the compression of cranial nerves by hypertrophic dura mater. The II, III, VI cranial nerves are often involved. HCP patients can also be complicated with cerebral venous sinus thrombosis (CVST), sinusitis, mastoiditis and other diseases. The blood routine and biochemical detection of HCP patients 

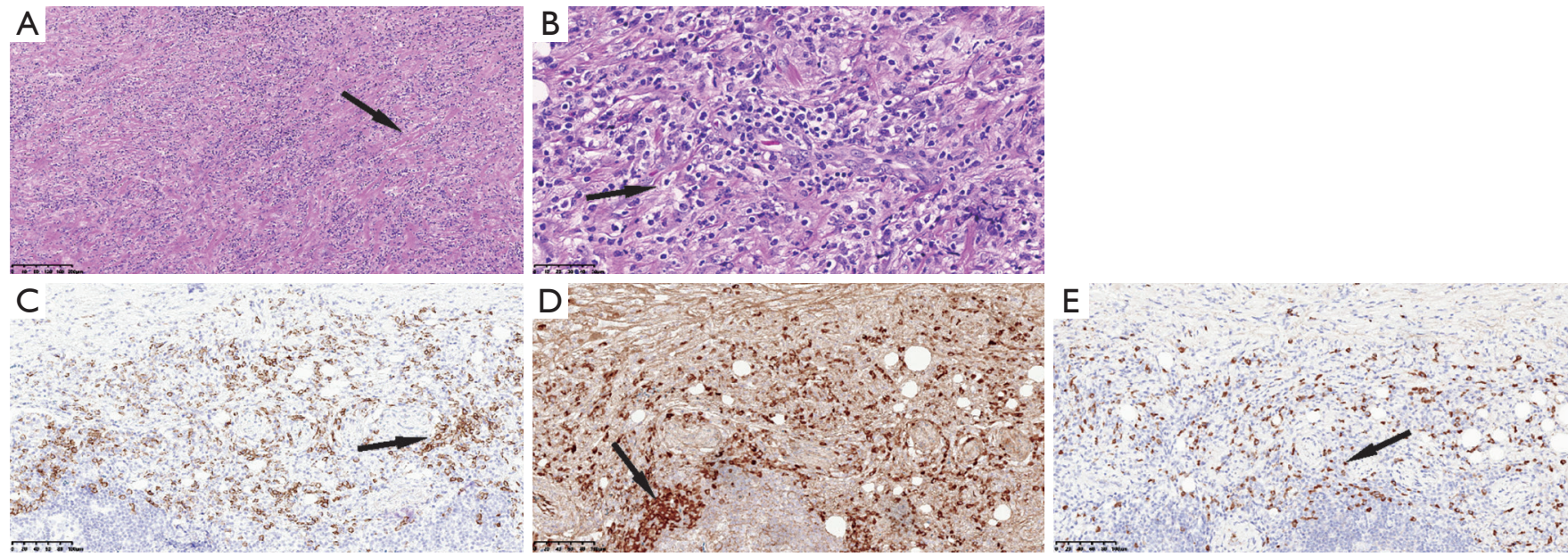

Figure 3 Pathological examination of brain tissue in patients with IgG4. (A) HE staining $(\times 100)$ results showed that the fibrous tissue was dense and proliferative, the area was storiform fibrosis, and the infiltration of inflammatory cells (arrow) was diffuse. (B) HE staining $(\times 400)$ results showed that there were a large number of plasma cells and lymphocytes infiltrated (arrow) in obliterative phlebitis. (C) Immunohistochemical staining $(\times 200)$ results showed that a large number of CD138 positive plasma cells (arrow) infiltrated. (D) Immunohistochemistry staining $(\times 200)$ results showed a large number of IgG positive plasma cells (arrow) infiltration. (E) Immunohistochemical staining $(\times 200)$ results showed that a large number of IgG4 positive plasma cells (arrow) infiltrated.
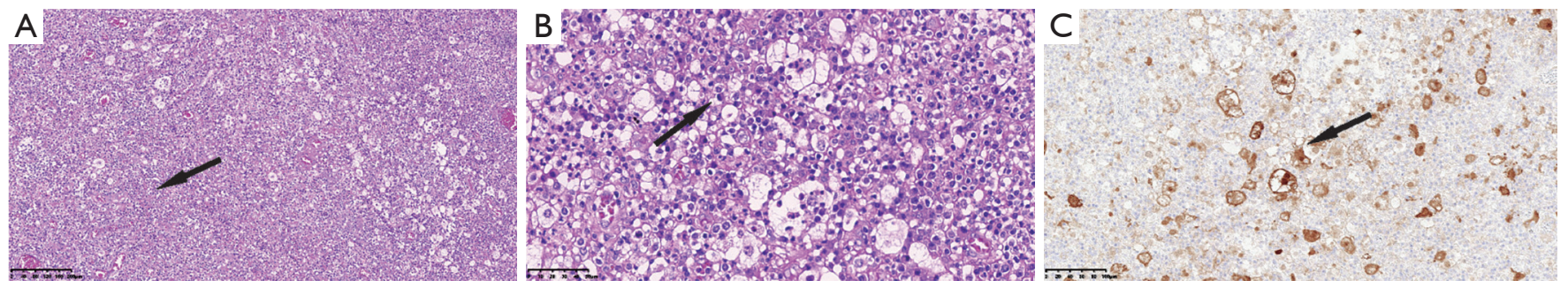

Figure 4 Pathological results of Rosai Dorfman disease. (A) HE staining ( $\times 100)$ results showed that fibrous tissue and vascular proliferation were accompanied by a large number of lymph, plasma cells (arrow) and neutrophils infiltration. (B) HE staining ( $\times 400)$ results showed that the volume of syncytial tissue cells (arrow) was huge and light stained, and many lymphoid and neutrophil cells could be seen in the cytoplasm. It was deeply stained with lymphoplasmacytes. (C) Immunohistochemical staining ( $\times 200)$ results showed that S-100 (arrow) was positive.

are usually non-specific while CSF pressure is normal or elevated, and the number of CSF cells and proteins can be normal or increased (14). The thickening dura mater can be learnt from cranial MRI images, and nodular or linear enhancement of thickened dura mater can be seen on enhanced scan, especially on T1 images. Most of the lesions were located in the cerebral falx, tentorium cerebelli, bilateral forehead, etc. In this study, the enhanced performance of MRI was also typical, mainly tentorium cerebelli and cerebral falx involved. The golden standard for the diagnosis of HCP is dura biopsy, which shows significant fibrous tissue proliferation in concentric arrangement appearing focal hyaline degeneration and inflammatory cell infiltration (mainly lymphocytes, eosinophils, plasma cells and fibroblasts). Immunohistochemistry shows that the number of $\mathrm{IgG}$ and IgG4 positive plasma cells increases. The number of IgG4 positive plasma cells in each high power field is more than 10 , IgG4/IgG is more than $40 \%$ $(6,15,16)$. The clinical symptom of HCP is non-specific, so the diagnosis should be combined with clinical symptoms, laboratory results, imaging manifestations and pathological results. Clinicians should improve their understanding of HCP to reduce the rate of missed diagnosis and misdiagnosis. Imaging examination is of guiding significance for the disease, and enhanced MRI is of great value in the diagnosis of HCP. The main enhanced scan is diffuse 
Table 2 Relevant diseases of pachymeningitis differential diagnosis

\begin{tabular}{|c|c|c|c|c|c|}
\hline Case & Gender & Age (year) & $\begin{array}{l}\text { Main clinical } \\
\text { manifestation }\end{array}$ & Laboratory examination & Imaging manifestation \\
\hline Rosai-Dorfman & Male & 61 & $\begin{array}{l}\text { Recurrent dizziness for } \\
5 \text { years }\end{array}$ & CRP 0.6 mg/L & $\begin{array}{l}\text { Left temporal space-occupying } \\
\text { lesion }\end{array}$ \\
\hline $\begin{array}{l}\text { Intracranial hypotension } \\
\text { syndrome }\end{array}$ & Male & 40 & Postural headache & $\begin{array}{l}\text { D-Dimer 1,600 } \mu \mathrm{g} / \mathrm{L} ; \text { CRP } \\
0.78 \mathrm{mg} / \mathrm{L}\end{array}$ & $\begin{array}{l}\text { Dura mater thicken } \\
\text { continuously }\end{array}$ \\
\hline Atypical meningioma & Male & 51 & $\begin{array}{l}\text { Headache for } 5 \\
\text { months, tongue left } \\
\text { deviation for } 4 \text { months }\end{array}$ & $\begin{array}{l}\text { D-Dimer } 562 \mu \mathrm{g} / \mathrm{L} ; \text { CRP } \\
0.43 \mathrm{mg} / \mathrm{L}\end{array}$ & $\begin{array}{l}\text { Abnormal signals in horizontal } \\
\text { trailing edge of clivus C3 }\end{array}$ \\
\hline $\begin{array}{l}\text { Central nervous system } \\
\text { leukemia }\end{array}$ & Male & 20 & $\begin{array}{l}\text { Fever for more than } \\
2 \text { months }\end{array}$ & CRP $1.2 \mathrm{mg} / \mathrm{L}$ & $\begin{array}{l}\text { Cranial fossa base meningioma } \\
\text { thicken }\end{array}$ \\
\hline
\end{tabular}

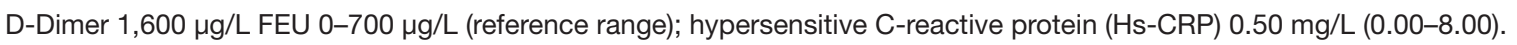

enhancement while nodular enhancement can also present, indicating poor prognosis. The probability of lesion and enhanced location is cerebellar tentorium $>$ cerebral falx $>$ frontal, temporal, parietal dura mater $>$ occipital dura mater. The most characteristic imaging manifestations are as follows: the enhancement of cerebral falx and cerebellar tentorium is "double-track sign" or "Mercedes-Benz sign" that there is "orbital" enhancement on both sides of the dura mater and the center of the dura mater is linear without enhancement. Among the common plain scan sequences, T1WI showed equal and slight hypointense signal, T2WI showed hypointense signal, or no abnormality was found. The patients met these manifestations. The finial diagnosis of HCP depended on pathology. The two groups of brain MRI showed abnormal thickening and enhancement of dura mater. The dura histology of the two diseases was totally different. Foreign scholars $(17,18)$ biopsy the dura mater with thickening of SIH, no abnormity was found by naked eyes, no abnormity was found near the bone surface of dura mater under microscope, and there was a thin layer of fibroblast in the amorphous matrix area near the brain surface of dura mater. In the meantime, the arachnoid cells appear diffuse and benign hyperplasia. Most patients can only make clinical diagnosis according to symptoms, signs and imaging, because a small number of people have clinical pathological examination. In current study, pathological examination of the dura mater was performed with the consent of the patient. Its results showed that hypertrophic dura mater presented non-specific inflammatory changes. If other special pathogens, such as mycobacterium tuberculosis and fungus, can be found in the course of pathological examination, it can provide a reliable basis for etiological diagnosis $(19,20)$. The diffuse fibrous tissue of dura was significantly increased in HCP dura biopsy living. In concentric arrangement, hyaline degeneration or caseous necrosis with chronic Infiltration of inflammatory cells such as lymphocytes, plasma cells and scattered eosinophils, It can form lymphoid follicles, some of which show chronic nonspecific granuloma with vasculitis. Moreover, the clinical symptoms and imaging manifestations of other dura thickening diseases diagnosed in our hospital were compared and analyzed, including Rosai-Dorfman disease, intracranial hypotension syndrome, tuberculous meningitis, atypical meningioma, central nervous system leukemia, etc. The imaging manifestation of Rosai-Dorfman disease was very similar to those of IgG4-RHP, so the diagnosis needs to be confirmed by serology and CSF examination, even confirmed by operation and pathology. Patients with intracranial hypotension syndrome usually have postural headache, and CSF examination showed that intracranial pressure is lower than the normal. Patients with tuberculous meningitis can have previous pulmonary tuberculosis. Laboratory examination can also provide an evidence for diagnosis of tuberculosis. Lesions can present in their brain parenchyma at the same time. Patients with atypical meningioma may not have previous headache, and often have chronic onset or no obvious clinical symptoms, so the diagnosis depends on the results of operation and pathology. Patients with central nervous system leukemia can be diagnosed with reference to the results of laboratory results. 


\section{Acknowledgments}

Funding: Zhejiang Natural Science FoundationAssociation of Mathematical and Physical Medicine (No. LSY19H180014); Zhejiang Basic Public Welfare Research Project (No. LGF19H220003).

\section{Footnote}

Reporting Checklist: The authors have completed the STROBE Reporting Checklist. Available at http://dx.doi. org/10.21037/apm-19-452

Data Sharing Statement: Available at http://dx.doi. org/10.21037/apm-19-452

Conflicts of Interest: Both authors have completed the ICMJE uniform disclosure form (available at http://dx.doi. org/10.21037/apm-19-452). The authors have no conflicts of interest to declare.

Ethical Statement: The authors are accountable for all aspects of the work in ensuring that questions related to the accuracy or integrity of any part of the work are appropriately investigated and resolved. The study was approved by the First Affiliated Hospital, School of Medicine, Zhejiang University ethics committee (No. 20191376) and conducted in accordance with the Declaration of Helsinki (as revised in 2013). Because of the retrospective nature of the research, the requirement for informed consent was waived.

Open Access Statement: This is an Open Access article distributed in accordance with the Creative Commons Attribution-NonCommercial-NoDerivs 4.0 International License (CC BY-NC-ND 4.0), which permits the noncommercial replication and distribution of the article with the strict proviso that no changes or edits are made and the original work is properly cited (including links to both the formal publication through the relevant DOI and the license). See: https://creativecommons.org/licenses/by-nc-nd/4.0/.

\section{References}

1. Vikse J, Haland S, Norheim KB. IgG4-related disease. Tidsskr Nor Laegeforen 2017;137.

2. Lu LX, Della-Torre E, Stone JH, et al. IgG4-related hypertrophic pachymeningitis: clinical features, diagnostic criteria, and treatment. JAMA Neurol 2014;71:785-93.

3. Maher M, Zanazzi G, Faust P, et al. IgG4-related hypertrophic pachymeningitis of the spine with MPOANCA seropositivity. Clin Imaging 2017;46:108-12.

4. Cação G, Calejo M, Alves JE, et al. Clinical features of hypertrophic pachymeningitis in a center survey. Neurol Sci 2019;40:543-51.

5. Hahn LD, Fulbright R, Baehring JM. Hypertrophic pachymeningitis. J Neurol Sci 2016;367:278-83.

6. Deshpande V, Zen Y, Chan JK, et al. Consensus statement on the pathology of IgG4-related disease. Mod Pathol 2012;25:1181-92.

7. Kawa S, Skold M, Ramsden DB, et al. Serum IgG4 Concentration in IgG4-Related Disease. Clin Lab 2017;63:1323-37.

8. Okazaki K, Umehara H. Current Concept of IgG4-Related Disease. Curr Top Microbiol Immunol 2017;401:1-17.

9. Umehara H, Okazaki K, Nakamura T, et al. Current approach to the diagnosis of IgG4-related disease Combination of comprehensive diagnostic and organspecific criteria. Mod Rheumatol 2017;27:381-91.

10. Blockmans D. IgG4-related disease. Acta Clin Belg 2018;73:11-5.

11. Yang YF. Histopathological features and pathological diagnosis of IgG4-related hepatobiliary diseases. Zhonghua Gan Zang Bing Za Zhi 2018;26:404-6.

12. Wallace ZS, Carruthers MN, Khosroshahi A, et al. IgG4-related disease and hypertrophic pachymeningitis. Medicine (Baltimore) 2013;92:206-16.

13. Tokushige S, Matsuura H, Hideyama T, et al. Hypertrophic Pachymeningitis as a Potential Cause of Headache Associated with Temporal Arteritis. Intern Med 2016;55:523-26.

14. De Virgilio A, de Vincentiis $M$, Inghilleri $M$, et al. Idiopathic hypertrophic pachymeningitis: an autoimmune IgG4-related disease. Immunol Res 2017;65:386-94.

15. Zhang X, Fujii T, Ogata H, et al. Cerebrospinal fluid cytokine/chemokine/growth factor profiles in idiopathic hypertrophic pachymeningitis. J Neuroimmunol 2019;330:38-43.

16. Slade SJ, Bauer EM, Stone VV, et al. Spinal IgG4Related Hypertrophic Pachymeningitis with Spinal Cord Compression: Case Report and Literature Review. World Neurosurg 2019;130:65-70.

17. Örgel A, Bender B, Stefanou MI, et al. Image Findings in Spontaneous Intracranial Hypotension (SIH). Rofo 2018;190:219-24.

18. Acar T, Golen MK, Golen M. Spontaneous Intracranial 
Hypotension (SIH) Following Soccer Game: Potential Role of MRI in the Treatment Response. Turk Neurosurg 2016;26:958-59.

19. Schubert RD, Wood M, Levin MH, et al. The severe side of the IgG4-related hypertrophic pachymeningitis disease spectrum. Neurol Neuroimmunol Neuroinflamm 2016;3:e197.

20. Smoleńska Ż, Masiak A, Zdrojewski Z. Hypertrophic pachymeningitis as an important neurological complication of granulomatosis with polyangiitis. Reumatologia 2018;56:399-405.
Cite this article as: Zhao $\mathrm{Y}, \mathrm{Xu} \mathrm{J}$. Imaging features, clinicopathological analysis and diagnostic strategy of IgG4related hypertrophic pachymeningitis. Ann Palliat Med 2020;9(5):2551-2558. doi: 10.21037/apm-19-452 